\title{
Samambaias e Licófitas do Cerro da Pedra do Lagarto, Santa Maria, Rio Grande do Sul, Brasil
}

\author{
Bianca Schindler ${ }^{1 *}$ (D), João Paulo Santos Condack ${ }^{2}$ (D), Felipe Gonzatti ${ }^{3}$ (D), \\ Liliana Essi' (1) \& Maurício Figueira' (1)
}

\author{
1 Universidade Federal de Santa Maria, Herbário SMDB, Avenida Roraima, 1000, Cidade Universitária \\ Camobi, $97105-900$, Santa Maria, RS, Brasil \\ 2 Pontifícia Universidade Católica do Rio de Janeiro, Herbário FCAB, Departamento de Biologia, 22451-900, Rio de Janeiro, RJ, Brasil \\ ${ }^{3}$ Universidade de Caxias do Sul, Herbário HUCS, Rua Francisco Getúlio Vargas, 1130 , Caxias do Sul, RS, Brasil \\ *Autor para correspondência: bia.schindler@gmail.com
}

Recebido em 04.IX.2019

Aceito em 06.VII.2021

DOI 10.21826/2446-82312021v76e2021017

\begin{abstract}
RESUMO - O inventário das samambaias e licófitas foi realizado no Cerro da Pedra do Lagarto que é um refúgio vegetacional com fitofisionomias distintas, uma florestal e outra campestre, situado no distrito de Santo Antão, ao norte do município de Santa Maria. O objetivo deste estudo foi contribuir para o conhecimento desta flora para a região Central do estado, que ainda é carente de informações sobre o grupo, fornecendo dados ecológicos e biológicos, além de uma chave dicotômica para a identificação das espécies observadas. Foram encontradas 34 espécies de samambaias e duas de licófitas, pertencentes a 28 gêneros de 14 famílias botânicas. Polypodiaceae foi a família com maior riqueza apresentando oito espécies seguida de Pteridaceae com sete. O substrato preferencial evidenciado foi o terrícola e a única espécie de porte arborescente foi Cyathea atrovirens. Os dados inventariados representam $9,5 \%$ das espécies de samambaias e licófitas para o estado do Rio Grande do Sul.
\end{abstract}

Palavras-chave: ecologia, flora, Mata Atlântica, Pampa, pteridófitas.

\begin{abstract}
Ferns and lycophytes from Cerro da Pedra do Lagarto, Santa Maria, Rio Grande do Sul, Brazil. The inventory of ferns and lycophytes was carried out in Cerro da Pedra do Lagarto, a vegetation refuge with distinct phytophysiognomies (forest and natural grassland, respectively) located in the district of Santo Antão, North of the Municipality of Santa Maria, Rio Grande do Sul State. The aim of this study was to contribute to the knowledge of the flora of fern and lycophytes in the poorly sampled central Region of the State, supplying ecologic and biological data and a dichotomous key for the identification of the species observed. There are 34 fern species and two lycophyte species, belonging to 28 genera of 14 botanical families. Polypodiaceae was the richest family with eight species, followed by Pteridaceae, with seven. Most species were terrestrial and the only arborescent specie was Cyathea atrovirens. The inventoried data represent $9.5 \%$ of the known species of ferns and lycophytes for the State of Rio Grande do Sul.
\end{abstract}

Keywords: Atlantic Rainforest, ecology, flora, Pampa, Pteridophytes.

\section{INTRODUÇÃO}

As samambaias e licófitas são as primeiras plantas da terra a apresentarem feixes vasculares, o que as difere das demais criptógamas, como as briófitas. Além destes caracteres, este grupo apresenta reprodução esporofítica, ou seja, não apresenta flores, frutos e sementes, o que as distingue dos demais grupos vasculares como as gimnospermas e angiospermas (Zuquim et al. 2008). Ademais, possuem uma variedade de formas de vida, hábitos e adaptações morfológicas, como: diferentes tipos de escamas, tricomas, caules, entre outros, que explicam a adaptação deste grupo a diferentes ambientes (Zuquim et al. 2008, Moran 2012, Terrazas 2013) e sua ampla distribuição desde as florestas tropicais até as regiões mais frias, como as tundras. Entretanto, a maior riqueza de espécies se encontra nas florestas tropicais das zonas montanhosas e diminui em direção às zonas temperadas (Moran 2012, Terrazas 2013).

A diversidade de samambaias e licófitas para o Brasil, com base nos dados atualizados da Flora do Brasil 2020 em construção (2020), é de 1.407 espécies, sendo 545 endêmicas. $\mathrm{O}$ estado do Rio Grande do Sul possui uma riqueza de espécies de cerca de 380 táxons, apesar do estado estar na nona posição do ranking em número de espécies (Prado et al. 2015, Flora do Brasil 2020 em construção 2019). Como destacado por Nervo et al. (2010), ainda há lacunas sobre a distribuição de táxons considerados de ampla distribuição por possuírem potencial de tolerância e adaptabilidade a diversas condições ambientais. Este fato pode ser explicado pela falta de coletas e pelos poucos trabalhos publicados em certas regiões do Estado. Em Santa Maria, houve o pioneirismo de Romeu Beltrão, que ao final da década de 1930 assumiu a disciplina de 
Botânica Aplicada à Farmácia (Marchiori \& Canto-Dorow 2011) e catalogou a flórula municipal (Beltrão 1962, 1965) registrando 1.074 espécies de fanerógamas. No entanto, as samambaias e licófitas não foram incluídas neste estudo. Atualmente, não há nenhum levantamento florístico realizado sobre samambaias e licófitas no município e as coletas são eventuais. Assim, conclui-se que esta região pode ser considerada carente de informações destes grupos e considerada prioritária para ter sua flora melhor conhecida.

O município de Santa Maria localiza-se na porção central do estado do Rio Grande do Sul, região marcada por variações fitofisionômicas, onde a metade norte é revestida originalmente por campos e matas e a metade sul, marcada pelo predomínio das áreas campestres do Pampa e matas ciliares (Lindman \& Ferri 1974, Marchiori 2009, Marchiori \& Canto-Dorow 2011). A diversidade florística e fitofisionômica para o município podem ser explicados justamente pela localização privilegiada (Marchiori \& Canto-Dorow 2011) com destaque para revestimento da Serra Geral com Floresta Estacional nas encostas (IBGE 1992) e com fragmentos de Floresta Ombrófila Mista nas partes altas do Planalto Médio (Lindman \& Ferri 1974), além de vastos campos naturais entremeados de matas ciliares e capões, nas planícies e coxilhas da Depressão Central (Marchiori 2009, Marchiori \& Canto-Dorow 2011).

Neste sentido, o objetivo deste estudo foi contribuir para o conhecimento da flora pteridofítica para a região central do estado, fornecendo dados ecológicos e biológicos, além de uma chave dicotômica para a identificação das espécies observadas.

\section{MATERIAL E MÉTODOS}

\section{Localização e caracterização da área de estudo}

A Pedra do Lagarto (29॰37’40”S, 5352’26”O) está localizada em uma propriedade privada no distrito de Santo Antão ao norte do município de Santa Maria, Rio Grande do Sul (Fig. 1), e possui aproximadamente 4 ha. Segundo Streck et al. (2008), o solo de Santa Maria está assentado sobre quatro litologias diferentes, as formações Santa Maria, Caturrita, Botucatu e Serra Geral. O local pode ser considerado um morro testemunho, com topo plano e limitado por escarpas, resultante da erosão pretérita das inúmeras camadas basálticas da formação Serra Geral, e que apresenta de forma predominante a formação geológica Botucatu. Esta formação é constituída de arenito eólico médio a fino, de coloração rosa-avermelhada, homogênea e com estratificação cruzada de grande porte depositado em ambiente desértico (Sartori 2009).

O clima é mesotérmico e úmido e, conforme a classificação de Köppen, é definido como tipo fundamental Cfa (Alvares et al. 2013). A temperatura média anual é de $19,1^{\circ} \mathrm{C}$, sendo o verão bastante quente em função da continentalidade e baixa altitude. Já o inverno é ameno, mas sujeito a geadas fracas a moderadas entre os meses de abril a setembro em decorrência do deslocamento de anticiclones polares migratórios. A precipitação pluviométrica mensal oscila entre 120,1 e 126,8 mm ao mês. O vento Norte é uma característica marcante do município por ser forte e quente, em virtude de sua localização geográfica entre o Planalto Médio e a Depressão Central (Heldwein et al. 2009).

O local é um mosaico vegetacional apresentando duas fitofisionomias distintas, uma florestal e outra campestre em área ecotonal entre os domínios fitogeográficos Mata Atlântica e Pampa (Fig. 1). Os campos estão localizados, sobretudo, no topo do cerro testemunho e nas rampas norte e leste, que estão em contato com as escarpas, e apresentam, de maneira geral, conspícuos afloramentos rochosos, oriundos dos tombamentos de volumosos blocos. Ainda pode-se classificar esta feição geomorfológica como um refúgio vegetacional, isto corroborado por outros levantamentos (Menezes \& Essi 2016, Schaefer \& Essi 2017, Scherer \& Essi 2017) e devido à presença de espécies de Cactaceae e do gênero Dyckia (Bromeliaceae), além de Agarista eucalyptoides (Cham. \& Schltdl.) G.Done e Trithrinax brasiliensis Mart., que ocorrem nos arredores do cerro e em pequenas populações, que são considerados elementos florísticos característicos destes refúgios no centro do Estado (Marchiori 2009, Soares et al. 2014). Esta flora relictual e de caráter xérico, possivelmente teve origem e maior expressão no pleistoceno, onde predominava uma vegetação campestre oriunda de um clima mais frio e seco na região (Bauermann et al. 2011).

Em relação à floresta, esta se concentra especialmente na porção sul da Pedra do Lagarto avançando até um pequeno riacho permanente. Esta formação pode ser classificada como Floresta Estacional Decidual (IBGE 1992), com dossel contínuo de até 15 metros de altura e sub-bosque pouco iluminado.

\section{Coleta, herborização, observações e identificação do material}

A coleta dos espécimes foi realizada em três expedições de junho de 2015 a março de 2019. Além da coleta do material botânico, também foram realizados registros fotográficos, observações das espécies no campo e anotações de dados ecológicos. Por se tratar de uma área relativamente pequena pode-se percorrer todos os ambientes e a amostragem foi detalhada.

Os espécimes foram coletados e herborizados seguindo a metodologia usual para plantas vasculares conforme descrita por Fidalgo \& Bononi (1984). O material testemunho coletado foi incorporado ao acervo do HDCF e as duplicatas foram enviadas para os herbários FCAB e HUCS (acrônimos segundo Thiers 2019).

A identificação foi realizada com auxílio de chaves dicotômicas, trabalhos taxonômicos, comparação com exsicatas do acervo dos herbários HDCF, FCAB, HUCS e virtuais, como Reflora (2019) e SpeciesLink (CRIA 2019). A nomenclatura dos nomes científicos das espécies seguiu a proposta pela Flora do Brasil 2020 em construção (2020). 

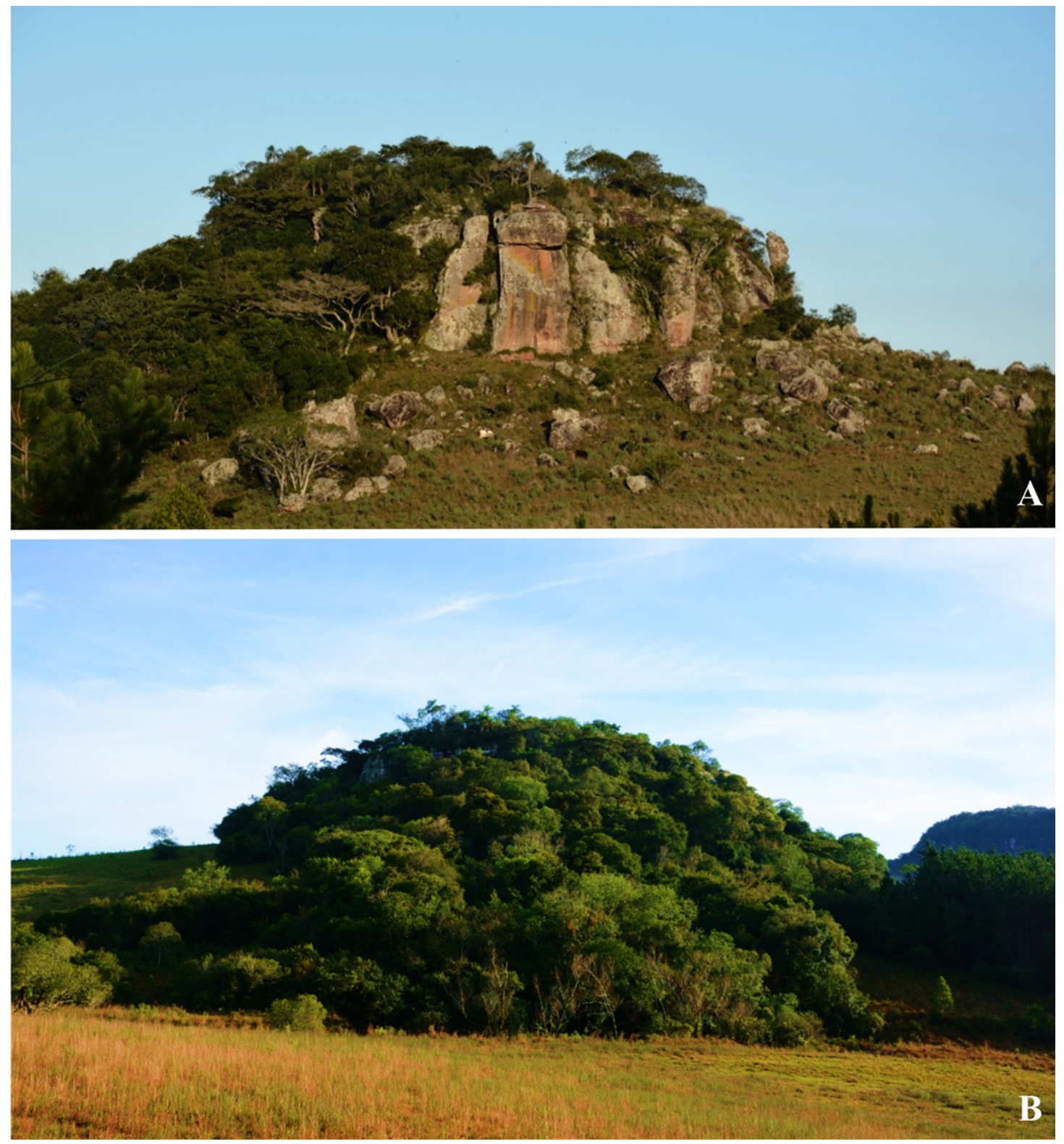

Figura 1. Cerro da Pedra do Lagarto. A. face norte e leste evidenciada pelos campos; B. face sul pela floresta (Fotos: M. Figueira).

As espécies foram classificadas de acordo com sua ocorrência nos diferentes ambientes, que foram delimitados de acordo com Oliveira-Filho (2009), sendo: campestre rupícola (CR), campestre ripícola (CRi), florestal (F) e florestal ripícola (FR). O hábito e o substrato de cada espécie foram registrados a partir das observações de campo e adotouse a classificação de Athayde Filho \& Windisch (2006).

\section{RESULTADOS E DISCUSSÃO}

No inventário foram registradas 36 espécies, pertencentes a 28 gêneros e 14 famílias (Tab. 1) que podem ser identificadas com o auxílio da chave dicotômica apresentada abaixo e com as pranchas (Figs. 3 a 8). O estado do Rio Grande do Sul apresenta cerca de 380 espécies, 112 gêneros e 34 famílias (Flora do Brasil 2020 em construção 2019) e desta maneira, pode-se concluir que o Cerro da Pedra do Lagarto apresenta cerca de $9,5 \%$ de espécies, $25 \%$ dos gêneros e $41 \%$ das famílias do estado. As samambaias representam a maioria das espécies (34 espécies, 26 gêneros e 12 famílias), sendo apenas dois táxons de licófitas registrados, Palhinhaea cernua (L.) Franco \& Vasc. (Lycopodiaceae) e Selaginella muscosa Spring. (Selaginellaceae). A baixa presença de licófitas neste estudo, é corroborado pelo fato deste grupo possuir menos de $1 \%$ da representatividade das plantas vasculares (Smith et al. 2006). Além do mais, a área de estudo se encontra em uma região ecotonal com o domínio fitogeográfico Pampa, onde poucas espécies ocorrem, afastado da Mata Atlântica do Sudeste do Brasil, que é um dos centros de diversidade para o grupo (Flora do Brasil 2020). 
Tabela 1. Espécies de Licófitas e Samambaias registradas no Cerro da Pedra do Lagarto, Santa Maria, RS. H = hábito, HER = herbáceo, AR = arborescente, $\mathrm{SB}=$ substrato, $\mathrm{Ter}=$ terrícola, $\mathrm{Cor}=$ corticícola, $\mathrm{Rup}=$ rupícola, $\mathrm{AM}=$ ambiente, $\mathrm{CR}=$ campestre rupícola, $\mathrm{CRi}$ : campestre ripícola $\mathrm{F}=$ florestal, $\mathrm{FR}=$ florestal ripícola.

\begin{tabular}{|c|c|c|c|c|}
\hline \multirow{2}{*}{ Táxons } & \multicolumn{3}{|c|}{ Observações ecológicas } & \multirow{2}{*}{ Acervo } \\
\hline & $\mathrm{H}$ & SUB & $\mathrm{AM}$ & \\
\hline \multicolumn{5}{|l|}{ Licófitas } \\
\hline \multicolumn{5}{|l|}{ Lycopodiaceae } \\
\hline Palhinhaea cernua (L.) Franco \& Vasc. & Her & Ter, Rup & $\mathrm{CR}, \mathrm{CRi}$ & HDCF 6734; FCAB 7205 \\
\hline \multicolumn{5}{|l|}{ Selaginellaceae } \\
\hline Selaginella muscosa Spring & Her & Ter & $\mathrm{CRi}$ & HDCF 6735; FCAB 7206 \\
\hline \multicolumn{5}{|l|}{ Samambaias } \\
\hline \multicolumn{5}{|l|}{ Anemiaceae } \\
\hline Anemia phyllitidis (L.) Sw. & Her & Ter & $\mathrm{F}$ & FCAB 7204 \\
\hline Anemia tomentosa (Sav.) Sw. & Her & Ter & $\mathrm{F}, \mathrm{CR}$ & HDCF 6724; FCAB 7232 \\
\hline \multicolumn{5}{|l|}{ Aspleniaceae } \\
\hline Asplenium claussenii Hieron. & Her & Ter & $\mathrm{F}$ & HDCF 6732; FCAB 7199 \\
\hline Asplenium gastonis Fée & Her & Rup & $\mathrm{F}$ & FCAB 7195 \\
\hline \multicolumn{5}{|l|}{ Athyriaceae } \\
\hline Deparia petersenii (Kunze) M.Kato & Her & Ter & FR & FCAB 7197 \\
\hline Diplazium cristatum (Desr.) Alston & Her & Ter & F, FR & HDCF 6736; FCAB 7196 \\
\hline \multicolumn{5}{|l|}{ Blechnaceae } \\
\hline Blechnum auriculatum Cav. & Her & Ter & $\mathrm{F}$ & FCAB 7201 \\
\hline Blechnum austrobrasilianum de la Sota & Her & Ter, Rup & $\mathrm{F}, \mathrm{CR}$ & FCAB 7233; 7215 \\
\hline Blechnum laevigatum Cav. & Her & Rup & $\mathrm{F}, \mathrm{CR}$ & HDCF 6726; FCAB 7221 \\
\hline Neoblechnum brasiliense (Desv.) Gasper \& V.A.O. Dittrich & Her & Ter & F, FR & HDCF 6744 \\
\hline Parablechnum cordatum (Desv.) Gasper \& Salino & Her & Ter & $\mathrm{CRi}$ & HDCF 6733; FCAB 7209 \\
\hline \multicolumn{5}{|l|}{ Cyatheaceae } \\
\hline Cyathea atrovirens (Langsd. \& Fisch) Domin. & Arb & Ter & $\mathrm{F}, \mathrm{CR}$ & FCAB $7219 ; 7213$ \\
\hline \multicolumn{5}{|l|}{ Dennstaedtiaceae } \\
\hline Pteridium esculentum (G. Forst.) Cockayne & Her & Ter & $\mathrm{CR}$ & HDCF 6739 \\
\hline \multicolumn{5}{|l|}{ Dryopteridaceae } \\
\hline Rumohra adiantiformis (G.Forst.) Ching & Her & Ter, Rup & $\mathrm{F}, \mathrm{CR}$ & HDCF 6746 \\
\hline \multicolumn{5}{|l|}{ Gleicheniaceae } \\
\hline Sticherus lanuginosus (Fée) Nakai & Her & Ter & $\mathrm{CR}$ & HDCF 7231; FCAB 7220 \\
\hline \multicolumn{5}{|l|}{ Hymenophyllaceae } \\
\hline Trichomanes pilosum Raddi & Her & Rup & $\mathrm{CR}, \mathrm{CRi}$ & HDCF 6725 ; FCAB 7224 \\
\hline \multicolumn{5}{|l|}{ Polypodiaceae } \\
\hline Campyloneurum nitidum (Kaulf.) C.Presl & Her & Ter, Rup & $\mathrm{F}$ & HDCF 6738, FCAB 7227 \\
\hline Microgramma squamulosa (Kaulf.) de la Sota & Her & Rup, Cor & $\mathrm{F}, \mathrm{CR}$ & HDCF 6737; FCAB 7217 \\
\hline Pecluma pectinatiformis (Lindm.) M.G.Price & Her & $\begin{array}{l}\text { Ter, } \\
\text { Rup }\end{array}$ & $\mathrm{F}$ & FCAB 7216; HUCS 44549 \\
\hline Phlebodium pseudoaureum (Cav.) Lellinger & Her & Rup & $\mathrm{F}$ & HDCF 6745 ; FCAB 7200 \\
\hline Pleopeltis hirsutissima (Raddi) de la Sota & Her & Rup & $\mathrm{F}, \mathrm{CR}$ & HDCF 6728; FCAB 7222 \\
\hline Pleopeltis minima (Bory) J. Prado \& R.Y. Hirai & Her & Rup, Cor & $\mathrm{F}, \mathrm{CR}$ & HDCF 6729 ; FCAB 7225 \\
\hline Pleopeltis pleopeltifolia (Raddi) Alston & Her & Rup, Cor & $\mathrm{F}, \mathrm{CR}$ & HDCF 6741 ; FCAB 7214 \\
\hline Serpocaulon latipes (Langsd. \& Fisch.) A.R.Sm. & Her & Ter, Rup, Cor & $\mathrm{F}, \mathrm{CR}$ & HDCF 6730; FCAB 7218 \\
\hline \multicolumn{5}{|l|}{ Pteridaceae } \\
\hline Adiantopsis chlorophylla (Sw.) Fée & Her & Ter & $\mathrm{CR}$ & HDCF 6747 \\
\hline Adiantum raddianum C.Presl & Her & Ter & F, FR & FCAB 7207; HUCS 44556 \\
\hline Doryopteris concolor (Langsd. \& Fisch.) Kuhn & Her & Ter & $\mathrm{F}$ & FCAB 7202 \\
\hline Doryopteris lorentzii (Hieron) Diels & Her & Ter, Rup & $\mathrm{F}$ & HDCF 6731; FCAB 7211 \\
\hline
\end{tabular}


Tabela 1. Cont.

\begin{tabular}{|c|c|c|c|c|}
\hline \multirow{2}{*}{ Táxons } & \multicolumn{3}{|c|}{ Observações ecológicas } & \multirow{2}{*}{ Acervo } \\
\hline & $\mathrm{H}$ & SUB & AM & \\
\hline Doryopteris pentagona Pic. Serm. & Her & Ter & $\mathrm{F}$ & HDCF 6742 \\
\hline Doryopteris triphylla (Lam.) Christ & Her & Ter & CR & FCAB 7212 \\
\hline Pteris brasiliensis Raddi & Her & Ter & $\mathrm{F}$ & FCAB 7198 \\
\hline \multicolumn{5}{|l|}{ Thelypteridaceae } \\
\hline Macrothelypteris torresiana (Gaudisch.) Ching & Her & Ter & $\mathrm{F}, \mathrm{FR}$ & FCAB 7236 \\
\hline Christella hispidula (Decne.) Holttum & Her & Ter & $\mathrm{CRi}$ & HDCF 6743; FCAB 7223 \\
\hline Amauropelta ptarmica (Kunze ex Mett.) Pic.Serm. & Her & Ter & FR & FCAB 7203 \\
\hline
\end{tabular}

A família Polypodiaceae obteve a maior representatividade ( 8 spp.), seguida de Pteridaceae (7 spp.), Blechnaceae (5 spp.) e Thelypteridaceae (3 spp.), totalizando $64 \%$ das espécies observadas no local. Esta riqueza de espécies está concentrada em quatro famílias de samambaias que pertencem a ordem Polypodiales (Smith et al. 2006). As famílias Polypodiaceae e Pteridaceae apresentam espécies com muitas adaptações as condições ambientais, o que pode explicar sua maior representatividade no local de estudo que possui mosaicos vegetacionais. Ainda, as espécies destas famílias possuem caracteres adaptativos, como a textura foliar coriácea, indumento foliar escamoso, deciduidade, rizoma carnoso, poiquilohidria e hábitos variados, que favorecem a colonização em locais mais secos em detrimento de outras famílias que não são capazes de se estabelecerem (Ranal 1991, Ranal 1993). Os gêneros Doryopteris (4 spp.), Pleopeltis e Blechnum (3 spp.), Anemia e Asplenium (2 spp.) apresentam maior riqueza, os demais estão representados apenas por uma espécie.

Sobre os aspectos ecológicos, o substrato terrícola foi o preferencial e de maneira exclusiva de 21 espécies $(60 \%)$. Estudos realizados no estado do Rio Grande Sul em remanescentes de Florestas Estacionais apontam as famílias Polypodiaceae e Pteridaceae entre as de maior riqueza de espécies. Ademais, o substrato preferencial das espécies destes mesmos estudos foi terrícola (Steffens \& Windisch 2007, Lehn et al. 2009, Gonzatti et al. 2014, Farias et al. 2014, Padoin et al. 2015, Moraes et al. 2018). Estes resultados provavelmente tem correlação com os aspectos adaptativos das espécies conforme supracitado.

Deparia petersenii (Kunze) M. Kato, Macrothelypteris torresiana (Gaudisch.) Ching e Christella hispidula (Decne.) Holttum são consideradas espécies naturalizadas e foram contabilizadas no número total de táxons registrados (Tab. 1) associadas ao ambiente ripícola, fato também registrado por Moraes et al. (2018). A área do levantamento possui influência de ações antrópicas, sobretudo da pecuária, favorecendo desta maneira, a ocorrência de espécies exóticas e/ou invasoras. Esta observação também é descrita por Zenni (2015) em que locais mais povoados e desmatados abrigam maior número de espécies naturalizadas, em virtude destes habitats suportarem uma alta riqueza de táxons e deste modo, também tendem a suportar elementos florísticos exóticos.

Cyathea atrovirens (Langsd. \& Fisch) Domin. foi a única espécie de hábito arborescente registrada. Entretanto, houve o registro de poucos indivíduos na área, fato também verificado por Lehn et al. (2009) em remanescentes de Floresta Estacional Decidual no Vale Taquari, RS. Notouse que os indivíduos de C. atrovirens que habitavam o topo do cerro e em afloramentos rochosos recebendo luz direta desenvolveram-se menos em altura que os que indivíduos que se encontravam no ambiente florestal, com luz difusa ou no sub-bosque e com solo mais desenvolvido. A resistência da espécie para este tipo de ambiente pode ser explicada por possuir alta plasticidade ecológica, visto que, foram capazes de se regenerarem até mesmo após uma queimada observada por Lehn \& Leuchtenberger (2008). Nesse sentido, Sticherus lanuginosus (Fée) Nakai, que pode ser observado em campos rupestres e especialmente em ambientes queimados (Gonzales \& Kessler 2011), e Doryopteris triphylla (Lam.) Christ em afloramentos rochosos, podem ser consideradas adaptadas a ambientes xéricos (Gonzatti et al. 2014), ambas registradas neste estudo exclusivamente em ambiente campestre rupícola (Fig. 2). De maneira similar, registrou-se Adiantopsis chlorophylla (Sw.) Fée e Pteridium esculentum (G. Forst.) Cockayne, sendo esta última uma espécie invasora e com resistência a queimadas (Sartorelli et al. 2018).

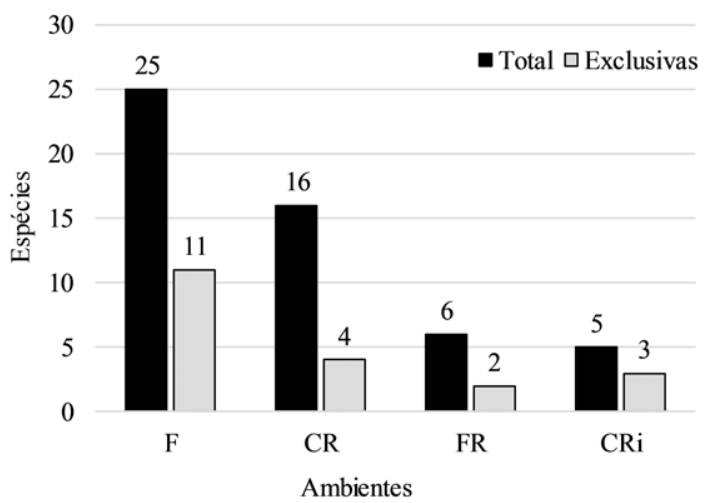

Figura 2. Ambientes de ocorrência das espécies observadas no Cerro da Pedra do Lagarto, Santa Maria, RS: F = florestal, $\mathrm{CR}=$ campestre rupícola, $\mathrm{FR}=$ florestal ripícola, $\mathrm{Cri}=$ campestre ripícola. 

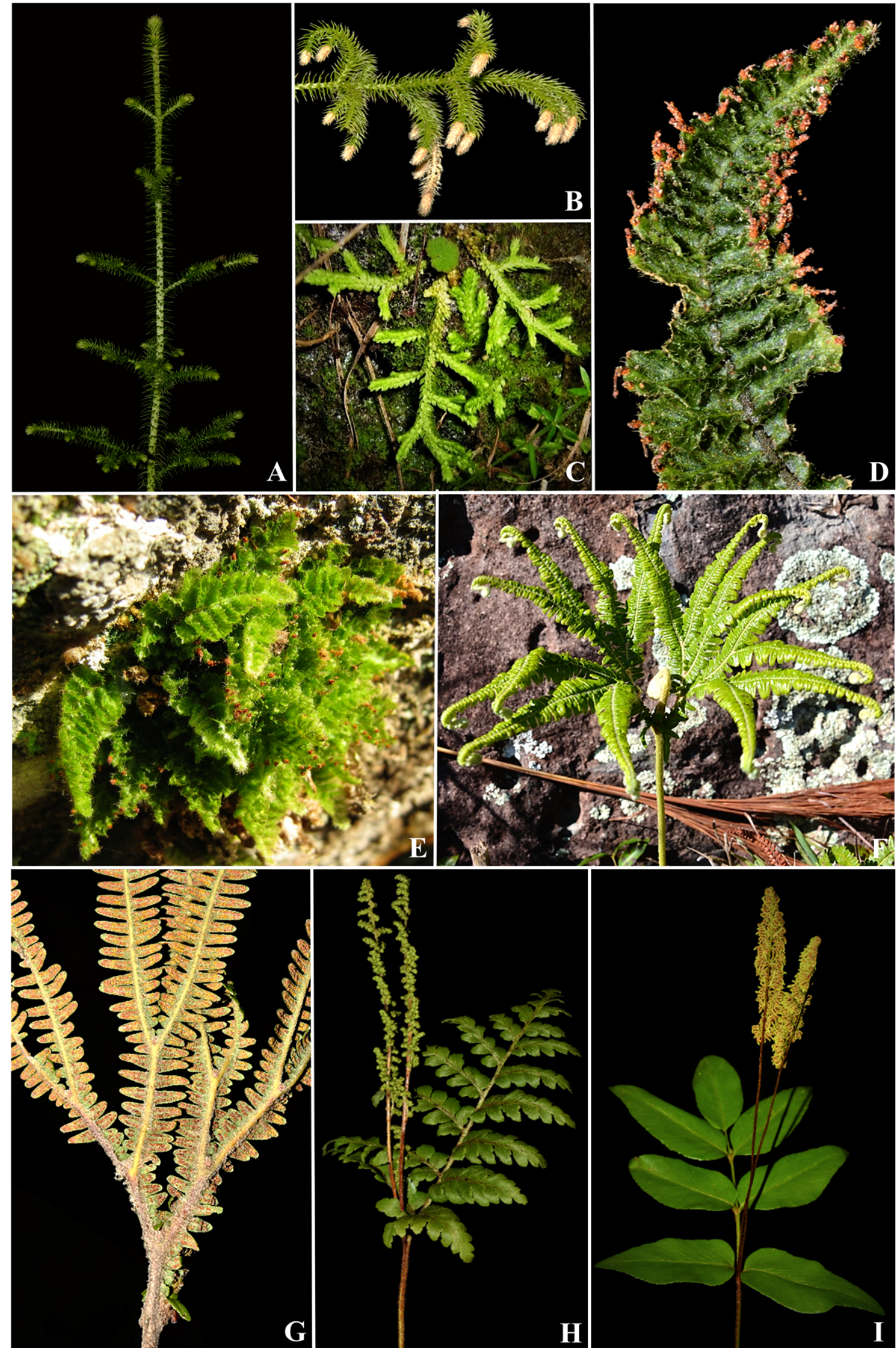

Figura 3. Samambaias e licófitas do Cerro da Pedra do Lagarto. A-B. Palhinhaea cernua; C. Selaginella muscosa; D-E. Trichomanes pilosum; F-G. Sticherus lanuginosus; H. Anemia tomentosa; I. Anemia phyllitidis (Fotos: B. Schindler \& M. Figueira). 

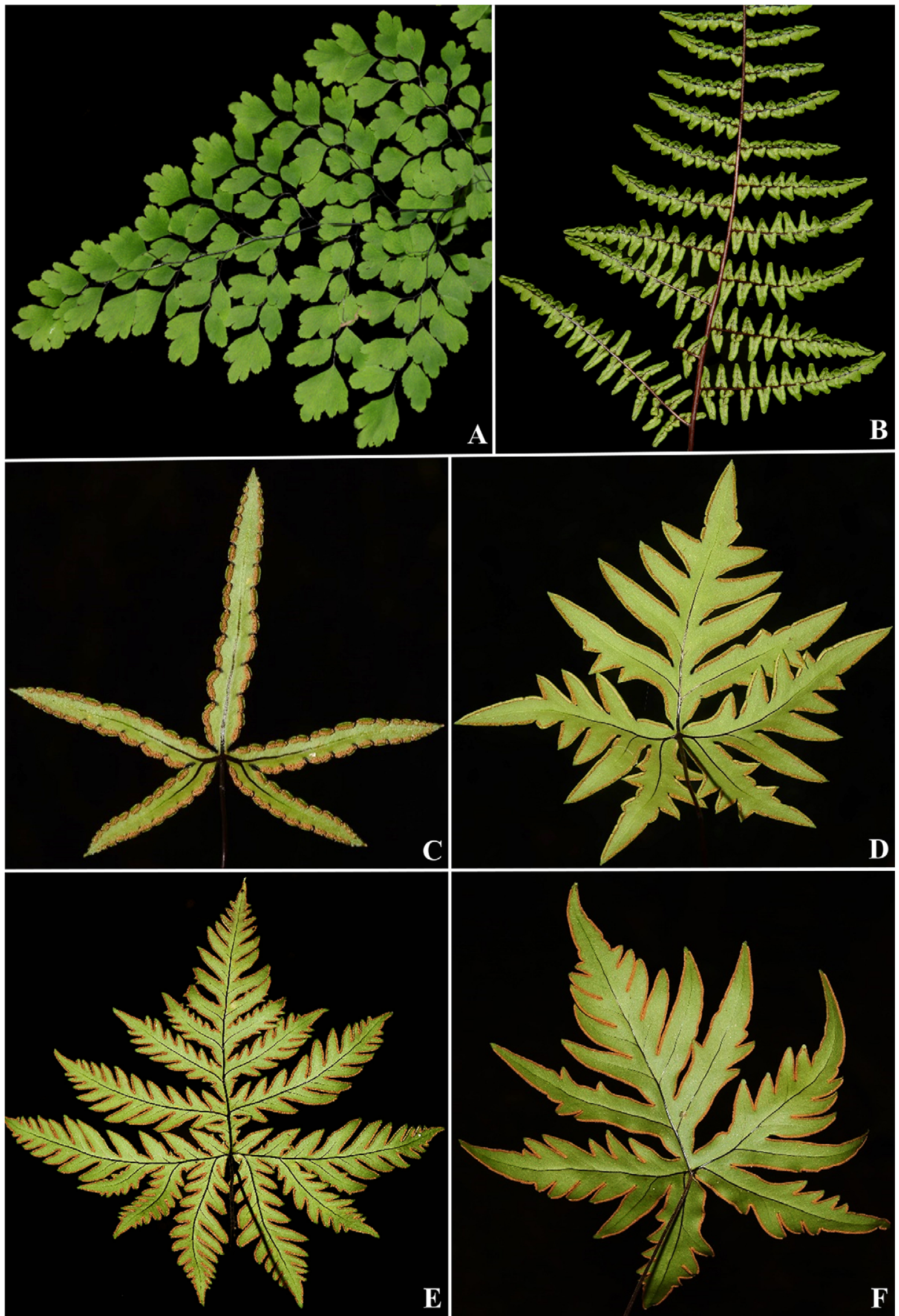

Figura 4. Samambaias e licófitas do Cerro da Pedra do Lagarto. A. Adiantum raddianum; B. Adiantopsis chlorophylla; C. Doryopteris triphylla; D. Doryopteris lorentzii; E. Doryopteris concolor; F. Doryopteris pentagona (Fotos: B. Schindler \& M. Figueira). 

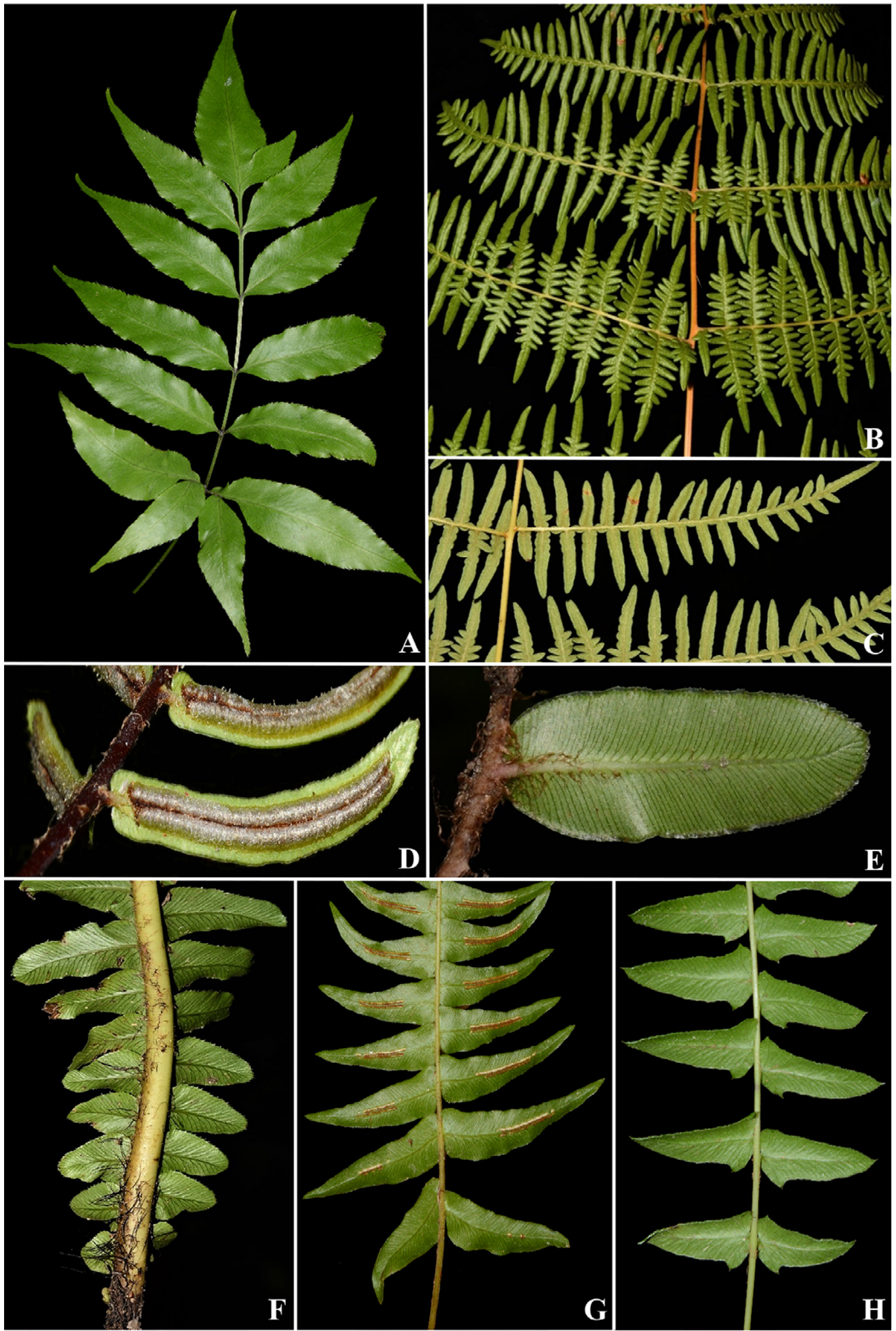

Figura 5. Samambaias e licófitas do Cerro da Pedra do Lagarto. A. Pteris brasiliensis; B-C. Pteridium esculentum; D-E. Parablechnum cordatum; F. Neoblechnum brasiliense; G. Blechnum austrobrasilianum; H. Blechnum auriculatum (Fotos: B. Schindler \& M. Figueira). 


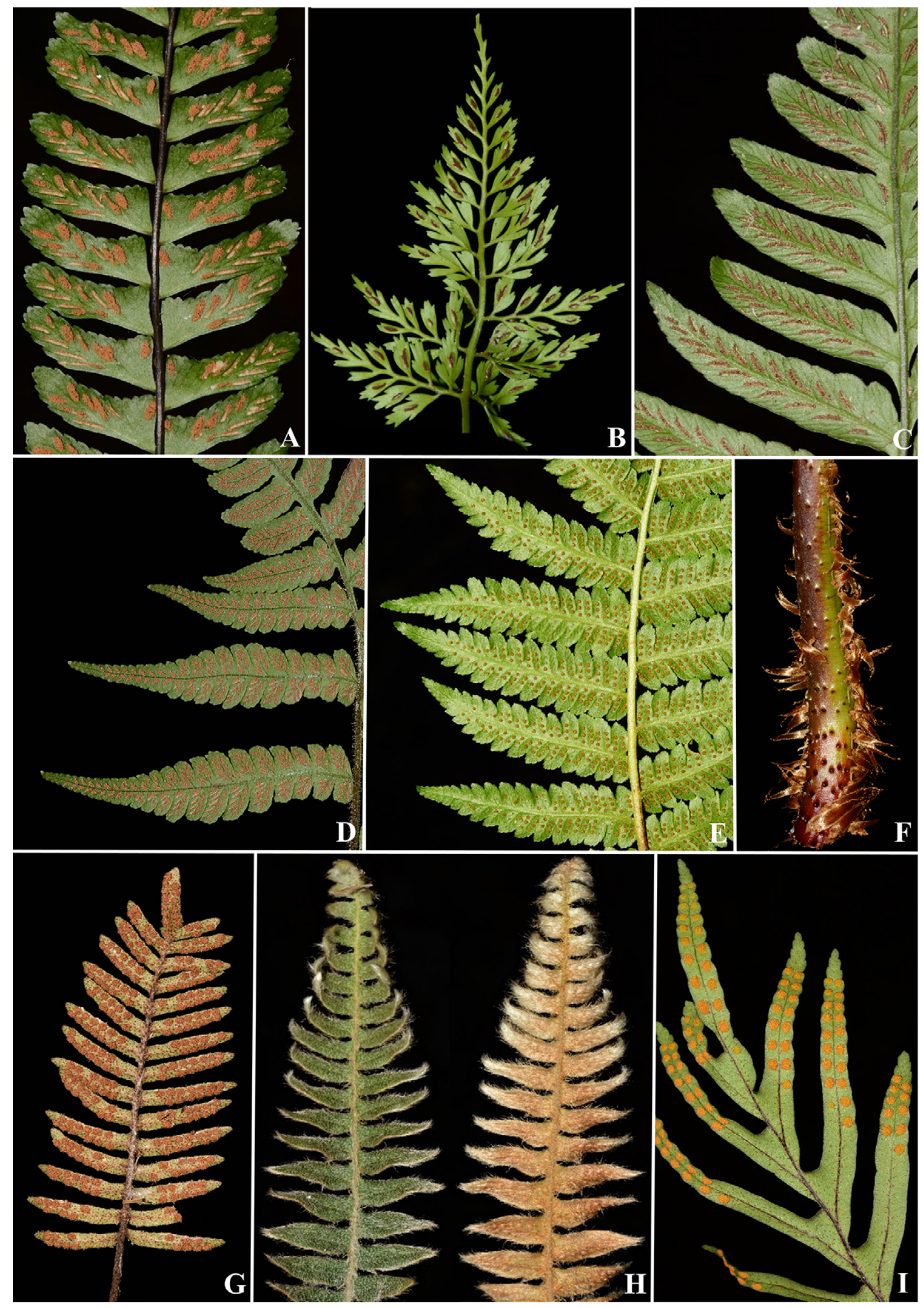

Figura 6. Samambaias e licófitas do Cerro da Pedra do Lagarto. A. Asplenium claussenii; B. Asplenium gastonis; C. Diplazium cristatum; D. Deparia petersenii; E-F. Cyathea atrovirens; G. Pleopeltis minima; H. Pleopeltis hirsutissima; I. Pleopeltis pleopeltifolia (Fotos: B. Schindler \& M. Figueira). 


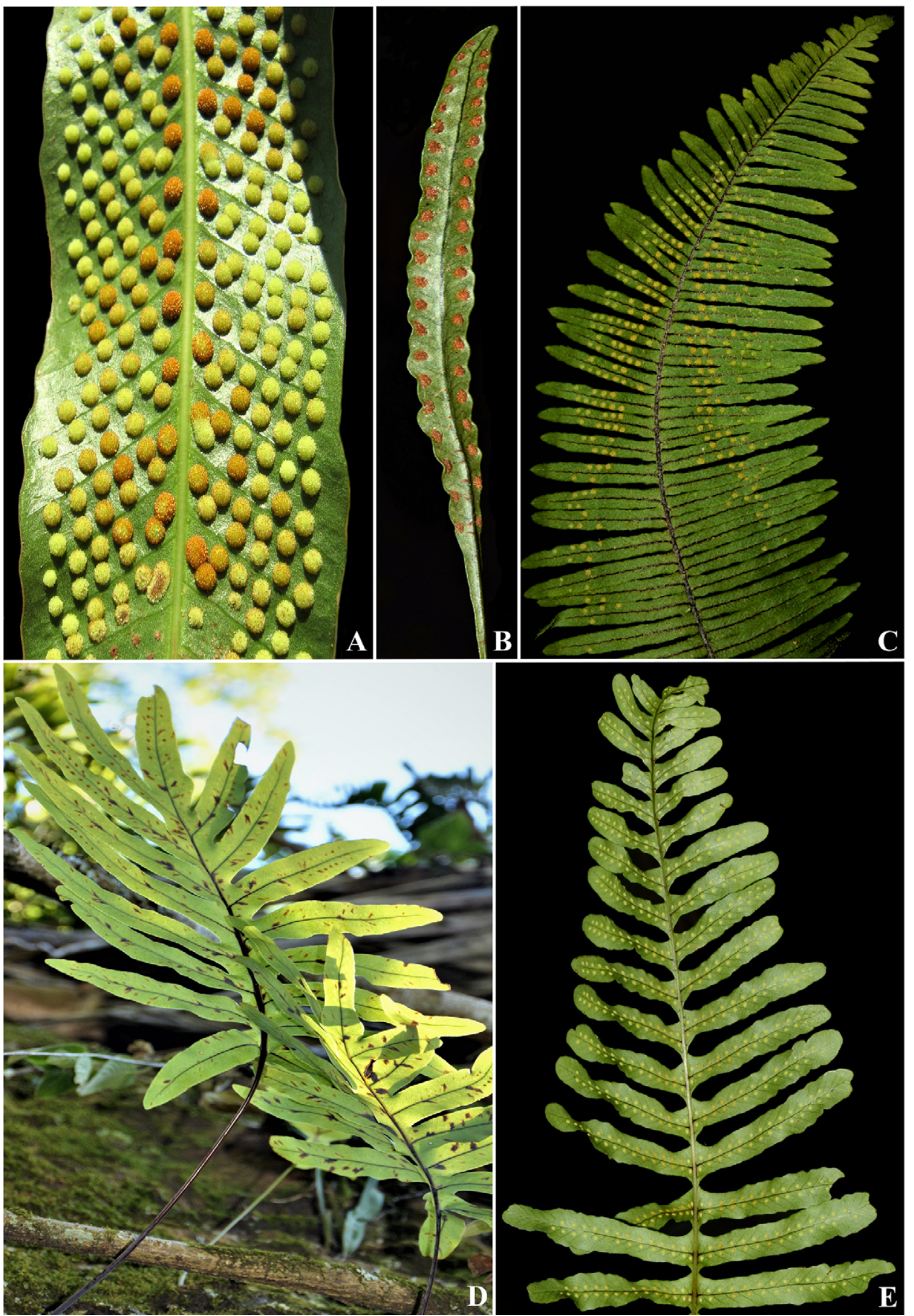

Figura 7. Samambaias e licófitas do Cerro da Pedra do Lagarto. A. Campyloneurum nitidum; B. Microgramma squamulosa; C. Pecluma pectinatiformis; D. Phlebodium pseudoaureum; E. Serpocaulon latipes (Fotos: B. Schindler \& M. Figueira). 

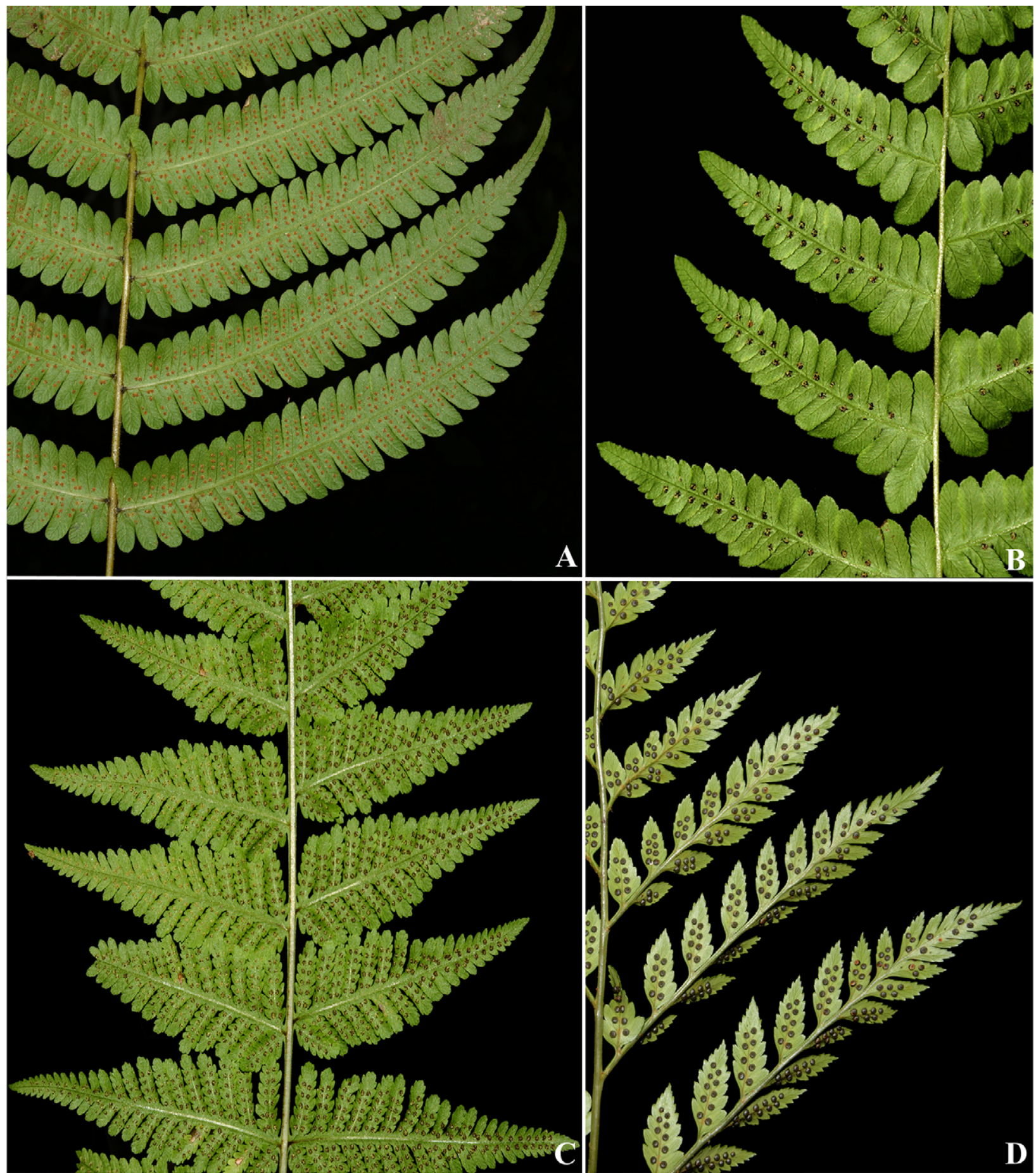

Figura 8. Samambaias e licófitas do Cerro da Pedra do Lagarto. A. Christella hispidula; B. Amauropelta ptarmica; C. Macrothelypteris torresiana; D. Rumohra adiantiformis (Fotos: B. Schindler \& M. Figueira).

As poucas espécies corticícolas registradas, mas não exclusivas deste substrato, foram da família Polypodiaceae (Tab. 1), corroborando com Smith et al. (2006), que menciona poucos representantes de substrato terrícola para esta família. Em um levantamento de epífitos vasculares em uma floresta de galeria na Depressão Central do estado do Rio Grande do Sul (Giongo \& Waechter 2004), a família Polypodiaceae foi uma das mais ricas, o que reflete sua capacidade adaptativa evoluída diante das restrições ecológicas que este tipo de ambiente exige.

As espécies Trichomanes pilosum Raddi e Phlebodium pseudoaureum (Cav.) Lellinger foram observadas, 
exclusivamente, aderidas à rocha da formação arenítica, circunstâncias estas já relatadas para estes táxons em outros estudos (Windisch 2014, Sehnem 1970).

$\mathrm{O}$ ambiente florestal foi o que proporcionou a maior observação de espécies (Fig. 2). De acordo com Senna \& Waechter (1997) o interior da floresta possui condições ecológicas bastante favoráveis à ocorrência de samambaias e licófitas, além de uma diversidade de adaptações das espécies aos diferentes nichos, que de certa forma caracteriza ecossistemas tropicais e subtropicais úmidos.
Por fim, mesmo em uma área relativamente pequena, supõe-se que a existência de uma diversidade de ambientes no mosaico vegetacional (Fig. 1) proporciona gradientes de umidade, luminosidade e substratos que supostamente favorecem a riqueza de famílias (14) e consequentemente de espécies. Este fato também foi registrado por Schwartsburd \& Labiak (2007), onde as proximidades fitofisionômicas entre campos, florestas e formações areníticas, são a possível explicação para a elevada riqueza de espécies no Parque Estadual de Vila Velha, Paraná.

\section{Chave para identificação de Samambaias e Licófitas para o Cerro da Pedra do Lagarto}

1. Plantas que possuem microfilos (folhas pequenas), geralmente até $1 \mathrm{~cm}$ de comprimento na maioria das espécies 2 Licófitas

2. Caule ereto; microfilos aciculares a lineares; estróbilos pendentes 3 a-b Palhinhaea cernua

2' Caule prostrado; microfilos ovais, oval-lanceolados ou oblongos; estróbilos não pendentes 3 c Selaginella muscosa

1' Plantas que possuem megafilos (folhas grandes), maiores que $3 \mathrm{~cm}$ podendo atingir vários metros de comprimento 3 Samambaias

3. Esporangióforos presentes; pinas basais modificadas, eretas 4

4. Lâmina 1-pinada; venação anastomosada; tricomas esparsos somente nas nervuras e na margem da lâmina 3 i Anemia phyllitidis

4' Lâmina com pinas medianas e basais 2-pinada-pinatífidas; venação livre e furcada; tricomas em ambas as faces da lâmina $3 \mathrm{~h}$ Anemia tomentosa

3' Esporangióforos ausentes; pinas basais não modificadas 5

5. Lâmina pseudo-dicotomicamente dividida, com gemas entre as bifurcações ... $3 \mathrm{f}-\mathrm{g}$ Sticherus lanuginosus

5' Lâmina não pseudo-dicotomicamente dividida, sem gemas entre as bifurcações

6. Soros na margem da lâmina

7. Soros de formato cônico com invólucro imerso no tecido laminar 3 d-e Trichomanes pilosum

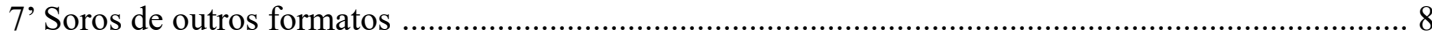

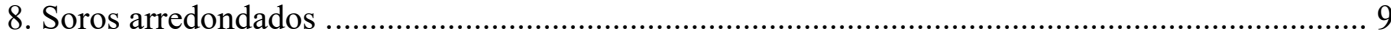

9. Habitat campestre; pínula pinatífida, contorno crenado; pecíolo, raque e peciólulos marromavermelhado 4 b Adiantopsis chlorophylla

9' Habitat florestal; pínula rombóide, contorno flabelado; pecíolo, raque e peciólulos nigrescentes 4 a Adiantum raddianum

8' Soros lineares 10

10. Lâmina palmatissecta ou pedada-pinatissecta 11

11. Soros descontínuos nos sinus 12

12. Lâmina profundamente palmatissecta; 3-5 segmentos com ápice linear e margem crenulada 4 c Doryopteris triphylla

12' Lâmina profundamente pedada-pinatissecta; > 6 segmentos com ápice acuminado e margem mais ou menos inteira 4 d Doryopteris lorentzii

11' Soros contínuos nos sinus 
13. Lâmina pedada-bi-tri-pinatissecta; margem dos segmentos pinatífidos; pecíolo sub-tereto (lado superior plano) 4 e Doryopteris concolor

13' Lâmina pedada-pinatissecta; margem dos segmentos mais ou menos inteiros; pecíolo tereto a caniculado $4 \mathrm{f}$ Doryopteris pentagona

10’ Lâmina de outras formas 14

14. Lâmina cartácea, pinas basais furcadas, margem serreada, plana, venação areolada a cladódroma, ambas as faces glabras 5 a Pteris brasiliensis

14' Lâmina coriácea, pinas basais 2-3-pinadas, margem inteira, revoluta, venação livre, face abaxial com tricomas 5 b-c Pteridium esculentum

6' Soros dispersos na lâmina ou dispostos ao longo da nervura central 15

15. Soros dispostos ao longo da nervura central das pinas e/ou segmentos 16

16. Fronde dimorfa; lâmina 1-pinada; base das pinas subcordada ou cordada 5 d-e Parablechnum cordatum

16' Fronde monomorfa ou hemidimorfa; lâmina pinatissecta; base das pinas de outras formas . .17

17. Escamas lineares de coloração nigrescente na base do pecíolo.... $5 \mathrm{f}$ Neoblechnum brasiliense

17 ' Escamas linear-lanceoladas ou estreitamente triangulares de coloração marrom na base do pecíolo 18

18. Fronde hemidimorfa; lado acroscópico das pinais basais livre com aurículas

$5 \mathrm{~h}$ Blechnum auriculatum

18 ' Fronde monomorfa; lado acroscópico das pinas basais parcial ou totalmente adnato à raque sem aurículas

19. Lâmina glabra, tricomas, quando presentes, somente na raque

$5 \mathrm{~g}$ Blechnum austrobrasilianum

19' Lâmina com tricomas conspícuos em ambas as faces e na raque.... Blechnum laevigatum

15' Soros não dispostos ao longo da nervura central das pinas e/ou segmentos 20

20. Soros lineares 21

21. Lâmina 1-pinada 6 a Asplenium claussenii

21' Lâmina 1-pinada-pinatífida ou 2-pinada

22. Lâmina 2-pinada na base tornando-se 1-pinada em direção ao ápice

$6 \mathrm{~b}$ Asplenium gastonis

22' Lâmina 1-pinada-pinatífida

23. Rizoma subereto a ereto; lâmina glabra em ambas as faces 6 c Diplazium cristatum

23' Rizoma horizontal; lâmina pubescente em ambas as faces $6 \mathrm{~d}$ Deparia petersenii

20' Soros arredondados

24. Pecíolo com espinhos marrons 6 e-f Cyathea atrovirens

24' Pecíolo sem espinhos 25

25. Escamas peltadas na lâmina 26

26. Lâmina pinada 6 g Pleopeltis minima

26' Lâmina pinatissecta 27 
27. Lâmina discolor (abaxial prateada a ferrugínea), segmentos linear-oblongo opostos a subopostos, ambas as faces densamente cobertas com escamas

$6 \mathrm{~h}$ Pleopeltis hirsutissima

27' Lâmina concolor, segmentos deltóides alternos, ambas as faces com escamas esparsas 6 i Pleopeltis pleopeltifolia

25' Escamas de outros tipos ou ausentes na lâmina 28

28. Lâmina simples inteira 29

29. Lâmina $>15 \mathrm{~cm}$ de compr. e $>3 \mathrm{~cm}$ de larg.; venação anastomosada; duas fileiras de soros entre as nervuras secundárias 7 a Campyloneurum nitidum

29' Lâmina $<10$ cm de compr. e $<2$ cm de larg.; venação areolada; soros na união de 2 ou 3 vênulas dentro da aréola mediana 7 b Microgramma squamulosa

28' Lâmina simples segmentada ou composta ................................................................. 30

30. Lâmina simples pectinada ou pinatissecta .............................................................. 31

31. Lâmina pectinada 7 c Pecluma pectinatiformis

31' Lâmina pinatissecta 32

32. Ápice da lâmina pinatífido, segmentos de margem ondulada, face abaxial com escamas lineares marrons-avermelhadas; pecíolo e rizoma verde-amarronzado com escamas marrons de margem hialina 7 e Serpocaulon latipes

32' Ápice da lâmina inteiro, segmentos de margem plana, face abaxial glabra; pecíolo e rizoma castanho-amarronzado densamente coberto de escamas castanho-claro e/ou hialinas $7 \mathrm{~d}$ Phlebodium pseudoaureum

30' Lâmina composta 1-pinada ou 2-pinada-pinatífida 33

33. Pinas basais e medianas 1-pinada-pinatífida 34

34. Ápice da pina longo-acuminado; face abaxial das pinas densamente coberta por tricomas aciculares de tamanhos irregulares; caule ereto

8 a Christella hispidula

34' Ápice da pina acuminado; face abaxial das pinas glabra ou esparsa a moderadamente pilosa; caule ereto a decumbente $8 \mathrm{~b}$ Amauropelta ptarmica

33' Pinas basais e medianas 2-pinada-pinatífida 35

35. Lâmina membranácea; pínulas pinatipartidas; indúsio inconspícuo, marrom; caule curto-reptante, densamente revestido no ápice por escamas linear-lanceoladas, castanhas, brilhantes 8 c Macrothelypteris torresiana

35' Lâmina cartácea-coriácea; pínulas pinatífidas; indúsio conspícuo, nigrescente; caule curto a longo-reptante, revestido com escamas ovadas a lineares, bicolores, marrom-claras com margem hialina $8 \mathrm{~d}$ Rumohra adiantiformis

\section{AGRADECIMENTOS}

Os autores agradecem à família Borin, proprietária do sítio onde se localiza a área de estudo, pelo acesso e o acolhimento. Ademais, ao Prof. Dr. Vinícius Antonio de Oliveira Dittrich pelo apoio e auxílio na identificação dos espécimes da família Blechnaceae.

\section{REFERÊNCIAS}

Alvares, C.A., Stape, J.L., Sentelhas, P.C., Gonçalves, J.L.M. \& Sparovek, G. 2013. Koppen's climate classification map for Brazil. Meteorologische Zeitschrift 6(22):711-728.

Athayde Filho, F. De P. \& Windisch, P.G. 2006. Florística e aspectos ecológicos das pteridóftas em uma floresta de Restinga no estado do Rio Grande do Sul, Brasil. Iheringia. Série Botânica 61(2):63-71. 
Bauermann, S., Behling, H. \& Pillar, V. 2011. Paleoambientes do cone sul da América do Sul. Ciência \& Ambiente 42:5-14.

Beltrão, R. 1962. Flórula fanerogâmica do município de Santa Maria, RS, Brasil. Boletim do Instituto de Ciências Naturais da Universidade Federal de Santa Maria 1:3-63.

Beltrão, R. 1965. Flórula fanerogâmica do município de Santa Maria, RS, Brasil. Boletim do Instituto de Ciências Naturais da Universidade Federal de Santa Maria 2:117-137.

CRIA(Centro de Referência e Informação Ambiental). 2019. Specieslink - simple search. Disponível em: http://www.splink.org.br/index. Acessado em: 08.04.2019.

Farias, A.P.S., Klein, C.L., Garlet, T.M.B. \& Essi, L. 2014. Pteridoflora da Universidade Federal de Santa Maria (UFSM), campus Palmeira das Missões, RS, Brasil. Acta Biológica Catarinense 1:5-21.

Fidalgo, O. \& Bononi, V.L.R. 1984. Manual prático de coleta, herborização e preservação. Instituto de Botânica do Estado de São Paulo, São Paulo. 61p

Flora do Brasil 2020 em construção. 2019. Samambaias e Licófitas. Jardim Botânico do Rio de Janeiro. Disponível em: http://floradobrasil.jbrj. gov.br/reflora/floradobrasil/FB128483>. Acessado em: 16.05.2019.

Flora do Brasil 2020. Samambaias e Licófitas. Jardim Botânico do Rio de Janeiro. Disponível em: http://floradobrasil.jbrj.gov.br/reflora/ floradobrasil/FB128483. Acessado em: 23.08.2020.

Giongo, C. \& Waechter, J.L. 2004. Composição florística e estrutura comunitária de epífitos vasculares em uma floresta de galeria na Depressão Central do Rio Grande do Sul. Revista Brasileira de Botânica 27(3):563-572.

Gonzales, J. \& Kessler, M. 2011. A synopsis of the Neotropical species of Sticherus (Gleicheniaceae), with descriptions of nine new species. Phytotaxa 31:1-54.

Gonzatti, F., Valduga, E., Wasum, R.A. \& Scur, L. 2014. Florística e aspectos ecológicos de samambaias e licófitas em remanescentes de matas estacionais deciduais da serra gaúcha, Rio Grande do Sul, Brasil. Revista Brasileira de Biociências 12(2):90-97.

Heldwein, A.B., Buriol, G.A. \& Streck, N.A. 2009. O clima de Santa Maria. Ciência \& Ambiente 38:43-58.

IBGE, Instituto Brasileiro de Geografia e Estatística. 1992. Manual Técnico da Vegetação Brasileira, Rio de Janeiro, 92 p.

Lehn, C.R. \& Leuchtenberger, C. 2008. Resistência ao fogo em uma população de Cyathea atrovirens (Langsd. \& Fisch.) Domin (Cyatheaceae) no Estado do Rio Grande do Sul, Brasil. Biotemas 21(3):15-21.

Lehn, C.R., Leuchtenberger, C. \& Hansen, M.A. 2009. Pteridófitas ocorrentes em dois remanescentes de Floresta Estacional Decidual no Vale do Taquari, Estado do Rio Grande do Sul, Brasil. Iheringia. Série Botânica 64:23-31.

Lindman, C.A.M \& Ferri, M.G. 1974. A vegetação no Rio Grande do Sul. Ed. Itatiaia limitada, Belo Horizonte; Ed. da Universidade de São Paulo, São Paulo, v. 2, 377 p.

Marchiori, J.N.C. 2009. A vegetação em Santa Maria. Ciência \& Ambiente 38:93-112.

Marchiori, J.N.C. \& Canto-Dorow, T. S. 2011. História da Botânica em Santa Maria. Balduínia 28:8-20.

Menezes, H.F. \& Essi, L. 2016. Leguminosas campestres do morro Pedra do Lagarto, Santa Maria, Rio Grande do Sul, Brasil. Balduínia 55:23-31.

Moraes, G.P., Marques, M.W., Bueno, M.L.\& Lehn, C.R. 2018. Samambaias e licófitas da sub-bacia do rio Fiúza, Noroeste do Rio Grande do Sul, Brasil. Pesquisas Botânica 71:97-107.

Moran, R.C. 2012. História Natural das Samambaias. TECC Editora, Florianópolis, $264 \mathrm{p}$

Nervo, M.H., Windisch, P.G. \& Lorscheitter, M.L. 2010. Representatividade da base amostral da pteridoflora do estado do Rio Grande do Sul
(Brasil) e novos registros de distribuição. Pesquisas Botânica 61:245258.

Oliveira-Filho, A.T. 2009. Classificação das fitofisionomias da américa do Sul Cisandina Tropical e Subtropical: proposta de um novo sistema - prático e flexível - ou uma injeção a mais de caos? Rodriguésia $60(2): 237-258$

Padoin, T.O.H., Graeff, V., Silva, V.L. \& Schmitt, J.L. 2015. Florística e aspectos ecológicos das samambaias e licófitas da mata ciliar de um afluente do Rio Rolante no Sul do Brasil. Pesquisas Botânica 68:335-348.

Prado, J., Sylvestre, L. Da S., Labiak, P.H., Windisch, P.G., Salino, A., Barros, I.C.L., Hirai, R.Y., Almeida, T.E., Santiago, A.C.P., KielingRubio, M.A., Pereira, A.F. De N., Øllgaard, B., Ramos, C.G.V., Mickel, J.T., Dittrich, V.A.O., Mynssen, C.M., Schwartsburd, P.B., Condack, J.P.S., Pereira, J.B.S. \& Matos, F.B. 2015. Diversity of ferns and lycophytes in Brazil. Rodriguésia 66(4):1073-1083.

Ranal, M.A. 1991. Desenvolvimento de Adiantopsis radiata, Pteris denticulata (Pteridaceae) e Polypodium latipes (Polypodiaceae) em condições naturais. Acta Botanica Brasilica 5(2):17-35.

Ranal, M.A. 1993. Desenvolvimento de Polypodium hirsutissimum Raddi (Pteridophyta, Polypodiaceae) em condições naturais. Acta Botanica Brasilica 7(2):3-15.

Reflora. 2019. Herbário Virtual. Disponível em: http://reflora.jbrj.gov. br/reflora/herbarioVirtual/. Acessado em: 02.04.2019.

Sartorelli, P.A.R., Benedito, A.L.D., Campos Filho, E.M., Sampaio, A.B. \& Gouvêa, A.P.M.L. 2018. Guia de plantas não desejáveis na restauração florestal. Agroicone, São Paulo, 71 p.

Sartori, P.L.P. 2009. Geologia e Geomorfologia de Santa Maria. Ciência \& Ambiente 1:19-42.

Schaefer, J. \& Essi, L. 2017. A checklist of Asteraceae from Pedra do Lagarto, Santa Maria, Rio Grande do Sul, Brazil. Check List 13(6):1075-1090.

Scherer, H.J. \& Essi, L. 2017. Levantamento florístico de Poaceae no morro da Pedra do Lagarto, distrito de Santo Antão, Santa Maria, RS. Caderno de Pesquisa 29(2):1-15.

Schwartsburd, P.B. \& Labiak, P.H. 2007. Pteridófitas do Parque Estadual de Vila Velha, Ponta Grossa, Paraná, Brasil. Hoehnea 34(2):159-209.

Sehnem, A. 1970. Polipodiáceas. In Reitz, R. Flora Ilustrada Catarinense. Herbário Barbosa Rodrigues, Itajaí, 173 p.

Senna, R.M. \& Waechter, J.L. 1997. Pteridófitas de uma floresta com araucária. 1. Formas biológicas e padrões de distribuição geográfica. Iheringia. Série Botânica 48:41-58.

Smith, A.R., Pryer, M.K., Schuettpelz, E., Korall, P., Schneider, H. \& Wolf, P.G. 2006. A classification for extant ferns. Taxon 55:705-731.

Soares, K.P., Longhi, S.J., Witeck Neto, L. \& Assis, L.C. 2014. Palmeiras (Arecaceae) no Rio Grande do Sul, Brasil. Rodriguésia 65(1):113-139.

Steffens, C. \& Windisch, P.G. 2007. Diversidade e formas de vida de pteridófitas no Morro da Harmonia em Teutônia-RS, Brasil. Pesquisas Botânica 58(3):375-382.

Streck, E.V., Kämpf, N., Dalmolin, R.S.D., Klamt, E., Nascimento, P.C. Do, Schneider, P., Giasson, E. \& Pinto, L.F.S. 2008. Solos do Rio Grande do Sul. EMATER-RS-ASCAR, 2 ed., Porto Alegre, p. 86-88.

Terrazas, E.F. 2013. Licófitas y helechos. Centro de Ecologia Difusión Simón I. Patiño. Bolivia Ecológica 68:1-20.

Thiers, B. 2019 (atualizado continuamente). Index Herbariorum: a global directory of public herbaria and associated staff. New York Botanical Garden's Virtual Herbarium. Disponível em: http://sweetgum.nybg. org/ih/. Acessado em: 25.04.2019.

Windisch, P.G. 2014. Hymenophyllaceae (Polypodiopsida) no Estado do Rio Grande do Sul. Pesquisas Botânica 65:15-48.

Zenni, R.D. 2015. The naturalized flora of Brazil: a step towards identifying future invasive non-native species. Rodriguésia 66(4):1137-1144.

Zuquim, G., Costa, F.R.C., Prado, J. \& Tuomisto, H. 2008. Guia de samambaias e licófitas da REBIO Uatumã. Attema. Manaus, 320 p. 